\title{
Uma breve reflexão sobre a plataforma virtual de aprendizagem da língua inglesa CNA Go
}

\author{
Marcos Oliveira Campos ${ }^{1}$ \\ Renata Marques Roberto²
}

\begin{abstract}
Resumo
Devido à sociedade contemporânea, cada vez mais "sem tempo", tornou-se recorrente o ensino através de ambientes virtuais de aprendizagem (AVAs). 0 mesmo ocorre com a língua inglesa como língua estrangeira. Por esse motivo, objetivou-se neste trabalho, analisar a plataforma virtual de ensino da língua inglesa CNA Go, e conferir se a mesma é realmente gamificada, conforme é dito em sua tela de apresentação. As características de jogos, definidas por Huizinga (1990), os princípios de aprendizagem encontrados em bons jogos, discutidos por Gee (2003; 2009) e os elementos de gamificação elencados por Vianna et al. (2013), entre outros teóricos, foram objeto de estudo nesta pesquisa. Objetivou-se, também, verificar se a interface deste AVA possui as características assinaladas por Oliveira (2007) como essenciais para que um AVA seja eficaz ao ensino da língua inglesa. Concluiu-se que realmente trata-se de um ambiente gamificado, cuja interface apresenta vários critérios assinalados como eficientes em relação ao ensino da língua inglesa como idioma estrangeiro, porém, algumas falhas ainda foram detectadas.
\end{abstract}

Palavras-chave: Ambientes Virtuais de Aprendizagem (AVA). Jogos. Gamificação. CNA Go.

\begin{abstract}
Due to the contemporary society, increasingly more with "no time", the teaching through Virtual Learning Environment (VLEs) became usual. The same happens with the English Language. Therefore, this research had as a goal, to analyze the virtual English Learning platform CNA Go, and check if it is really gamified according to its declaration on its welcome screen. The game characteristics, defined by Huizinga (1990); the learning principles found in good games, according to Gee (2003; 2009) and the gamification elements defined by Vianna et al. (2013), among other theorist, were the research objects in this paper. It also had as a goal, to check if this VLE interface has the essential characteristics of an efficient English Teaching VLE, defined by Oliveira (2007). The conclusion was that CNA Go is really a gamified VLE and its interface has a lot of criteria considered efficient to the English Language Teaching, but some failures were yet detected.
\end{abstract}

Keywords: Virtual Learning Environment (VLE). Games. Gamification. CNA GO.

\section{Introdução}

Este artigo apresenta dados de uma análise sobre a plataforma virtual de ensino de Língua Inglesa, CNA Go, que se diz gamificada. 0 que justifica a necessidade desta análise é verificar se os elementos de jogos estão realmente presentes neste ambiente virtual de aprendizagem (AVA) e fazer uma breve observação se sua interface possui algumas

\footnotetext{
${ }^{1}$ Mestrando no Programa de Pós-Graduação em Linguística Aplicada da Universidade de Taubaté - UNITAU. Atua como Coordenador de Tecnologia da Informação na Secretaria Municipal de Educação de Paraty - RJ.

2 Mestranda no Programa de Pós-Graduação em Linguística Aplicada da Universidade de Taubaté - UNITAU. Atua no magistério municipal de Passa Vinte - MG.
}

LínguaTec, Instituto Federal de Educação, Ciência e Tecnologia do Rio Grande do Sul, Bento Gonçalves v. 4 , n. 2 , p. 1-28, nov. 2019 . 
características consideradas essenciais para que um ambiente virtual, voltado à aprendizagem, seja eficaz.

A pesquisa foi norteada pelas seguintes perguntas: Essa plataforma é mesmo gamificada? Sua interface possui os elementos necessários para um ambiente virtual voltado para a aprendizagem?

A expectativa é que a pesquisa disserte, embasada cientificamente, sobre um ambiente gamificado, ao ponto de levar a reflexão a desenvolvedores e professores em relação a estes ambientes, para que de fato o processo de aprendizagem do aluno de língua estrangeira culmine com êxito. Espera-se que esta pesquisa possa contribuir para o desenvolvimento de plataformas virtuais de aprendizagem, com recursos cada vez mais direcionados ao usuário contemporâneo, facilitando, assim, o processo de aquisição virtual de novos conhecimentos.

Os dados foram analisados à luz das concepções de jogos, difundidas por Huzinga (1990), que apontam as características e elementos dos jogos. Também como pressupostos teóricos, foram consideradas as teorias de James Paul Gee (2003), sobre os princípios de aprendizagem, provindos dos vídeos games; as mecânicas de jogos, assinaladas por Vianna et al. (2013) e as definições de gamificação, bem como os elementos a serem observados em uma interface voltada à aprendizagem, definida por Oliveira (2018).

Os procedimentos metodológicos seguiram a seguinte dinâmica: a pesquisadora vivenciou a experiência de aluna, utilizando, de forma crítica, todas as ferramentas oferecidas pela plataforma. Tal interação foi realizada no período de testes proporcionados por este AVA. Foi feita uma coleta de dados, e, posteriormente, uma análise observando os critérios relativos à gamificação. Percebeu-se de que a plataforma virtual de ensino da língua inglesa, CNA Go, realmente apresenta vários elementos, características e princípios de jogos, ou seja, ela é gamificada. Foi verificado, ainda, que sua interface atende a critérios considerados essenciais para que um ambiente virtual voltado à aprendizagem seja eficaz, tais como interatividade, usabilidade, multimodalidade, entre outros. 


\section{Fundamentação teórica}

Neste artigo, tomaremos como referência, as características de jogos, apresentadas pelo historiador e linguista holandês Johan Huizinga (1990); os princípios de aprendizagem embutidos nos jogos, percebidos pelo pesquisador americano Jean Paul Gee (2003 e 2009); as mecânicas de jogos, assinaladas pelo presidente da MJV Tecnologia \& Inovação Ysmar Vianna et al. (2013); e as definições de gamificação citadas pelo empresário Stephen B. Burke (2015); bem como os elementos a serem observados em uma interface voltada à aprendizagem, definidas por Oliveira (2007).

\subsection{0 jogo, segundo Huizinga}

Huizinga (1990), em sua obra intitulada Homo Ludens, define o jogo como um fenômeno social, presente nos diversos processos culturais, concebidos dentro de um espaço e tempo definidos, com regras pré-estabelecidas; as quais, ao serem quebradas, destroem o espírito do jogo.

O jogo é uma atividade ou ocupação voluntária, exercida dentro de certos limites de tempo e espaço, segundo regras livremente consentidas, mas absolutamente obrigatórias, dotado de um fim em si mesmo, acompanhado de um sentimento de tensão e alegria e de uma consciência de ser diferente da vida cotidiana (HUIZINGA, 1990, p. 33).

O autor ainda define, dentre outras, as seguintes características fundamentais dos jogos:

1) Atividade voluntária e livre: é possível, em qualquer momento, adiar ou suspender o jogo. Jamais é imposto pela necessidade física ou pelo dever moral, e nunca constitui uma tarefa, sendo sempre praticado nas "horas de ócio". (HUIZINGA, 1990, p. 10)

2) Não é vida corrente, nem vida real: o jogo é, na verdade, uma evasão da realidade para uma esfera de atividade temporária. É um intervalo na vida cotidiana, capaz de absorver o jogador de maneira intensa e total.

o jogo é isolado: é distinto da vida "comum".

3) Limites de tempo e espaço: o jogo acontece dentro de uma limitação de espaço e tempo pré-determinada, possuindo um caminho e um sentido próprio. 
4) Regras: o jogo ocorre dentro de regras pré-estabelecidas. Uma vez que há a menor desobediência a essas regras, o jogo acaba. Por isso ele pode criar ordem e desordem.

5) Repetição: a repetição no jogo deve ser permitida tantas vezes quantas forem necessárias, dando assim oportunidade, em qualquer instante, de análise de resultados;

6) Dinamismo: o jogo deve ser permanentemente dinâmico.

2.2 Princípios de aprendizagem: Jean Paul Gee

Jean Paul Gee (2003), em What video games have to teach us about learning and literacy, defende o uso dos "bons videogames" e sua aplicabilidade voltada ao aprendizado. 0 autor estabelece algumas condições para que a experiência seja transformada em aprendizado conforme descrito a seguir:

1) A experiência pode ser usada para resolver problemas futuros se ela for estruturada por objetivos específicos;

2) As experiências precisam ser interpretadas, ou seja, é preciso pensar na ação e depois da ação em como os objetivos se relacionam com o novo raciocínio na nova situação. Isso significa tirar lições e antecipar-se para saber onde essas lições podem ser usadas;

3) As pessoas aprendem melhor quando têm feedback imediato durante suas experiências, pois elas podem identificar e avaliar seus erros;

4) Os aprendizes precisam de amplas oportunidades para aplicar suas experiências prévias e simular as novas situações;

5) Os alunos precisam aprender a interpretar suas experiências e explicá-las para outras pessoas, seus pares ou especialistas, pois isso é uma boa forma de aprender. A interação social, a discussão, a apresentação são importantes.

Em sua obra intitulada de Bons videogames e boa aprendizagem, Gee (2009) estabelece alguns princípios de aprendizagem incorporados pelos jogos: Identidade, relativo a requerer o aprendiz assuma uma nova identidade, comprometa-se com o mundo no qual irá atuar, tome um personagem ou construa um novo; Interação, pois em um bom jogo, as 
palavras são colocadas em contexto, em uma relação interativa do jogador com o mundo; Produção, pois os jogadores são produtores, não apenas consumidores, sendo assim, os jogadores ajudam a escrever o mundo do jogo em que eles vivem; Assumir riscos, pois os jogadores são encorajados a assumir a explorar e testar novidades. Num jogo perder pode ser produtivo; Customização, pois os jogadores podem customizar o jogo para que ele se adéque ao estilo de jogar e aprender de cada um. Jogos têm geralmente diferentes níveis de dificuldade e permitem que os jogadores resolvam os problemas de diferentes maneiras. Agência, pois_os jogadores sentem o sentido real de gerenciamento e controle; Problemas exequíveis, pois pesquisas mostram que quando os aprendizes são deixados em um espaço permissivo eles tendem a criar soluções criativas para problemas complexos. Desafio $e$ consolidação, pois bons jogos oferecem aos jogadores uma quantidade de problemas desafiadores e deixam que eles resolvam esses problemas até que tenham virtualmente rotinizado e automatizado suas soluções; Just in time $e$ on demand, "a tempo" e "sob demanda". Em jogos, as informações verbais são dadas no momento em que os jogadores precisam usá-las para tê-las quando precisarem; Significado situado, pois pesquisas recentes sugerem que as pessoas só sabem realmente o que uma palavra significa e aprendem novas quando conseguem ligar essas palavras a certas experiências, ou seja, a certas imagens, diálogos, sons com os quais a palavra se relaciona. As palavras têm significado situado em diferentes contextos de uso; Agradavelmente frustrante, pois bons jogos são desafiadores e factíveis ao mesmo tempo, e isso é altamente motivador para os aprendizes; Sistema de pensamento, pois bons jogos encorajam jogadores a pensar sob a forma de relações, não sob eventos, fatos e habilidades isolados. Em um mundo complexo, um mundo global, tal maneira de pensar é crucial; Explore, pense lateralmente, repense objetivos, já que os jogos encorajam os jogadores a explorar tudo antes de tomar decisões; Ferramentas inteligentes e conhecimento distribuído, pois os jogos possuem ferramentas inteligentes que ajudam o jogador nas jogadas. O conhecimento é distribuído entre os jogadores, cada jogador contribui com uma habilidade distinta; Limes multifuncionais, pois em jogos de múltiplos jogadores, cada jogador tem uma habilidade diferente. Cada jogador deve dominar sua própria função, mas ter entendimento suficiente das especialidades dos outros para colaborarem e funcionarem juntos. As pessoas se unem em razão de esforços 
comuns, e não por causa de sua raça, classe ou gênero; Desempenho antes de competência, pois bons videogames operam por princípio contrário ao da maioria das escolas: desempenho antes de competência.

\subsection{Gamificação}

Vianna et al. (2013), definem gamificação como a utilização de mecanismos de jogos que objetiva auxiliar na resolução de algum problema ou simplesmente engajar um público em alguma atividade. De acordo com os autores, a mecânica dos jogos, ou seja, os componentes utilizados para recompensar e, assim, estimular os usuários, são divididos a partir de cinco elementos, os quais devem ser cuidadosamente planejados para que não sejam ou banalizados, ou sejam inalcançáveis:

1) Status: é a forma mais explícita de se distribuir recompensas, podendo ser feito por meio dos rankings dos participantes, distribuição de pontos ou premiações que destaquem os jogadores perante os demais. A notoriedade em relação aos outros participantes, ou seja, o reconhecimento público é considerado o elemento mais forte dentre os cinco.

2) Acesso: é outro ponto estimulador nos sistemas de recompensa para engajar os participantes em seus objetivos. A possibilidade de entrada em um ambiente, a permissão de uso de alguns recursos privilegiados, etc. ou a negação desses recursos servem para impulsionar os sujeitos no alcance das próximas etapas.

3) Influência: pode ser concedida aos jogadores de forma direta ou indireta. A primeira permite que o usuário tenha a sensação de controle no jogo, podendo ser concedida a ele por meio de algum benefício ou conquista durante o jogo. A segunda acontece quando um jogador tem a possibilidade de interferir positiva ou negativamente, voluntária ou involuntariamente no andamento de outrem.

4) Brindes e Giftings: Os primeiros seriam a forma mais simples de se recompensar, fornecendo itens, pistas, vidas, caracterizando-se como uma forma de feedback positivo. Os giftings, por sua vez, são uma forma de brinde concedida por outros 
jogadores na forma de troca de benefícios, fazendo com que os jogadores estabeleçam elos na criação de comunidades mais duradouras.

Segundo Vianna et al. (2013), o estabelecimento de regras e feedback é importante para garantir o engajamento dos sujeitos no percurso da atividade.

Segundo Burke (2015):

Design de experiência digital, o qual apresenta a jornada que os jogadores terão de percorrer utilizando-se de elementos como: a sequência dos passos do jogo, o reconhecimento do ambiente e a decodificação do roteiro. Diz respeito a todo o ambiente e o que o jogador deverá fazer para concluir as etapas do jogo (BURKE, 2015, p. 6).

\section{Ambiente Virtual de Aprendizagem (AVA)}

Ambientes Virtuais de Aprendizagem (AVA) são ambientes de gestão e construção integradas de informação, comunicação e aprendizagem online (OLIVEIRA, 2007). Segundo Oliveira (2007), eles permitem integrar múltiplas mídias, linguagens e recursos, apresentar informações de maneira organizada, desenvolver interações entre pessoas e objetos de conhecimento, elaborar e socializar produções tendo em vista atingir determinados objetivos.

Oliveira (2007) aponta ainda algumas características que uma interface de ambiente de aprendizagem deve apresentar para que seja eficiente em sua função de ensinar. São elas:

1) Usabilidade: refere-se à interação do usuário com o ambiente virtual. Deve-se levar em conta os seguintes aspectos:

- Facilidade de aprendizagem do sistema: tempo e esforços necessários para que se atinja um certo nível de desempenho

- Facilidade de uso: considera-se o esforço físico e cognitivo

- Grau de satisfação do usuário: prazer em trabalhar com o sistema

- Flexibilidade: possibilidade de usar o sistema de maneira criativa, realizando 0 maior número de tarefas com a mesma função e comando. 
- Produtividade: considera se a produção seria menor, caso não utilizasse o sistema.

2) Consistência: o design da interface dos AVA deve adotar o mesmo estilo, pois uma vez que o usuário o domina, concentra-se apenas no conteúdo.

3) Integridade estética: cores, gráficos e animações devem ser elementos facilitadores de aprendizagem e não objetos de entretenimento.

4) Estabilidade: consiste na não mudança de interface sem o conhecimento $e$ consentimento do usuário.

0 autor ainda fala sobre a linguagem de hipertextos e hipermídias e aponta algumas características que devem estar presentes nos AVAs. São elas:

- É sempre mais seguro dar ao usuário uma lista de itens para a seleção do item desejado do que fazê-lo digitar a escolha;

- O controle deve estar sempre com o usuário;

- Deve-se usar metáforas do mundo real, sempre que possível. Exemplos típicos são pastas para arquivos, cestos de lixo, botões para 'empurrar' com o mouse;

- Feedback e diálogos são importantes: as ações do usuário devem ter uma pronta resposta do sistema, bem como o sistema deve informar ao usuário o que está se passando. Um exemplo típico: o sistema informa sobre o andamento do processamento de informações e/ou do carregamento de arquivos.

Com base no referencial teórico apresentado, procedemos à análise da plataforma CNA Go. 


\section{Análise da plataforma virtual de aprendizagem CNA Go}

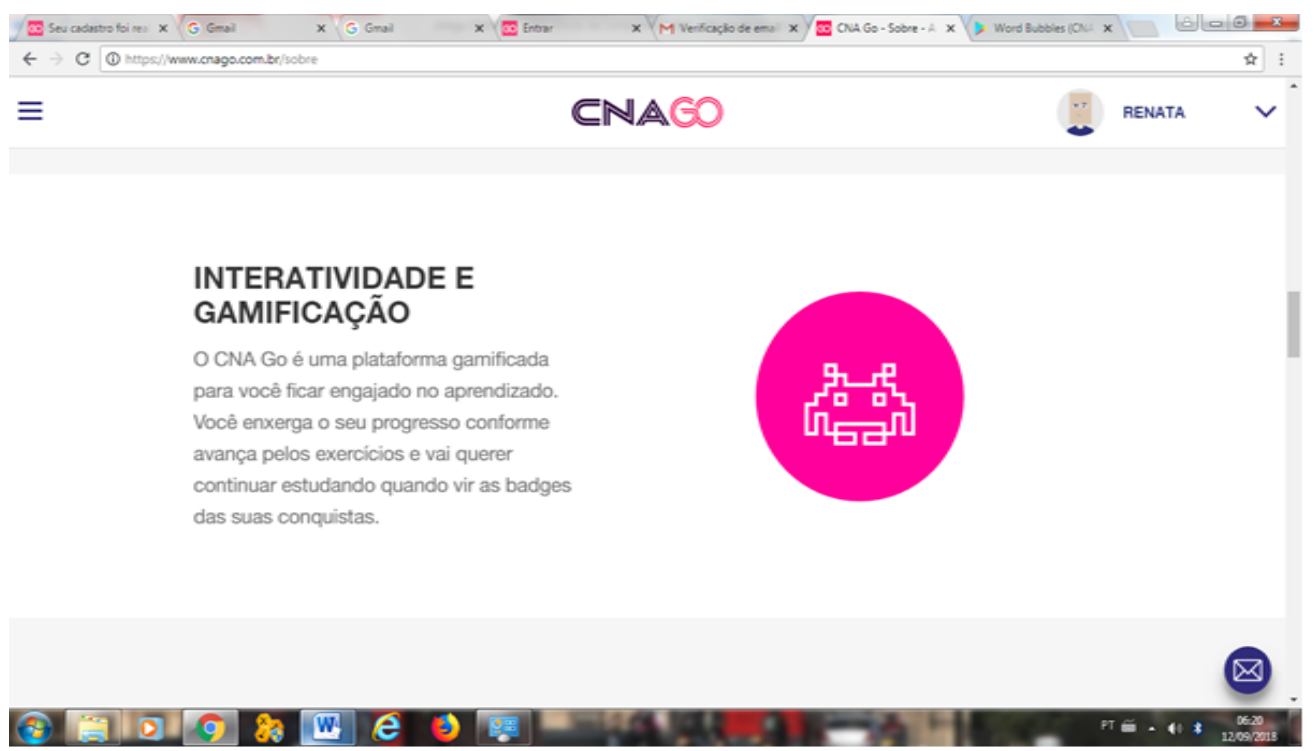

Figura 1. Sítio.

Fonte: Sítio CNA Go.

Esse ambiente virtual de aprendizagem, que se diz gamificado, é voltado ao ensino das línguas inglesa e espanhola. Foi analisado somente o ambiente da língua inglesa. Tal análise procedeu no período experimental de quinze dias, no qual a pesquisadora vivenciou a experiência do aluno e interagiu, de forma crítica, com tal plataforma, a fim de identificar as características apontadas no capítulo anterior, as quais supõe-se que tornem estes AVAs ambientes eficientes para o aprendizado da língua inglesa como idioma estrangeiro.

0 foco da pesquisa foi verificar se a plataforma CNA Go possui os elementos apontados na fundamentação teórica, relativos a jogos e gamificação, com o objetivo de verificar se esta plataforma é realmente gamificada ou não. Uma breve observação sobre alguns critérios para avaliar a qualidade de uma interface voltada ao aprendizado, também foi alvo de tal pesquisa. 


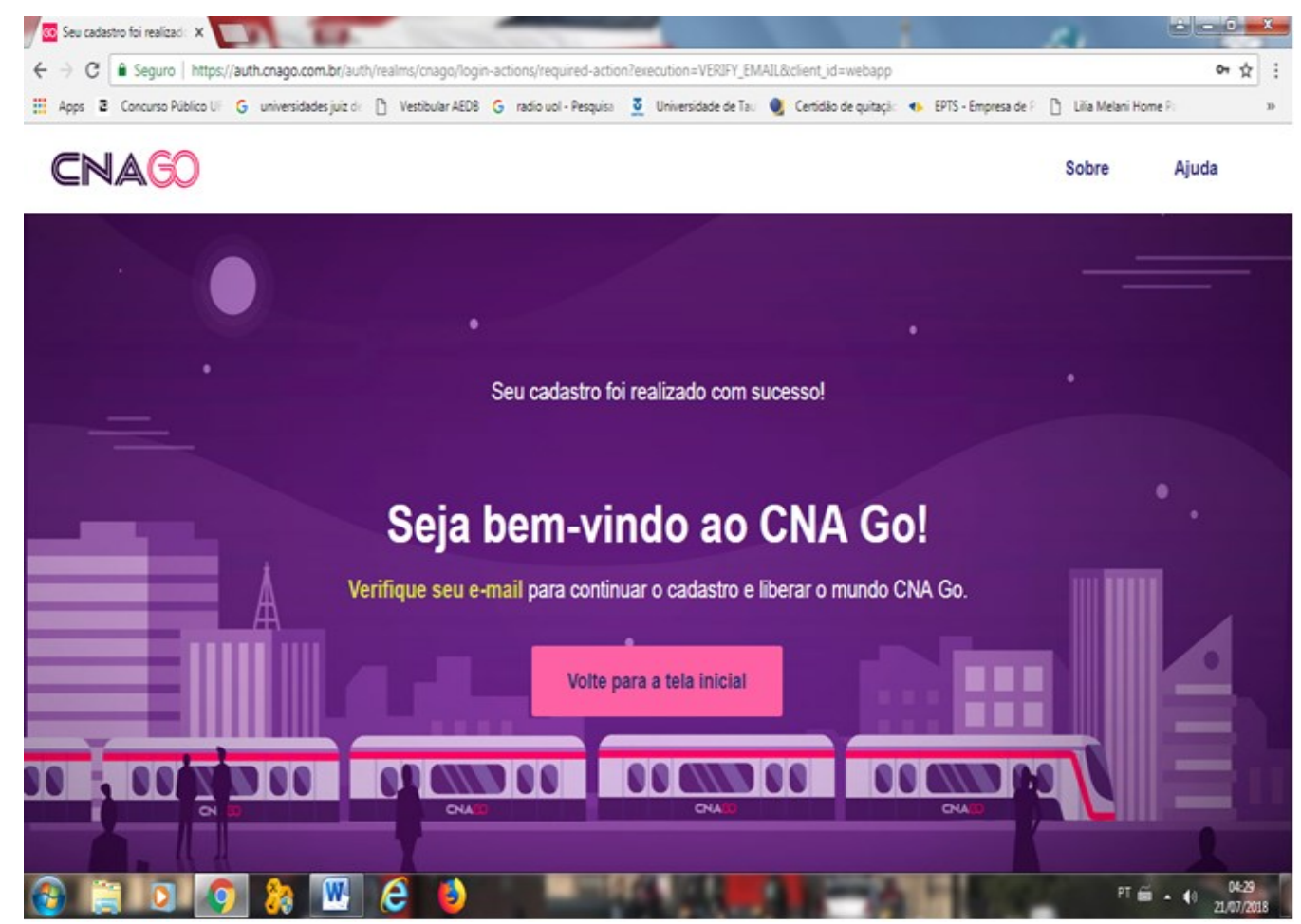

Figura 2. Tela de "boas-vindas"

Fonte: Sítio CNA Go.

O design da interface de "boas-vindas" da plataforma apresenta uma estação de trem, sugerindo que ao cadastrar-se, o aluno/usuário ingressará em uma viagem. Daí o nome CNA Go, que sugere uma partida, uma vez que o verbo "go", provindo da língua inglesa, significa "ir", em português. De acordo com Oliveira (2007), o "design dos ambientes virtuais de ensino a integridade estética: cores, gráficos e animações devem ser elementos facilitadores da aprendizagem" (OLIVEIRA, 2007, p. 4). Burke (2015) ainda define o design de experiência digital como "a jornada que o usuário tem que percorrer" (BURKE, 2015, p. 6). A ideia de iniciar uma viagem causa ao usuário um sentimento de euforia e sugere uma fuga do cotidiano, fatores que estão presentes na definição de jogo, apresentada por Huizinga (1990). 


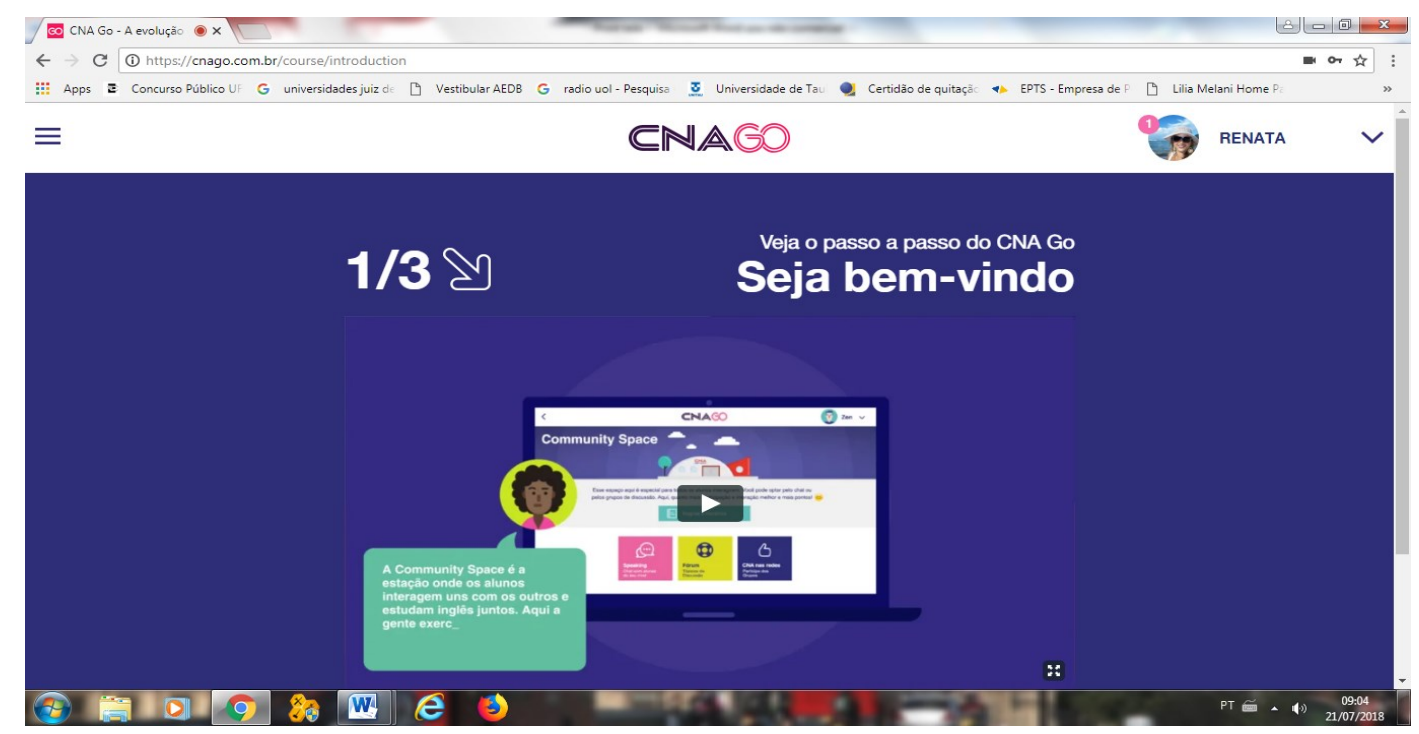

Figura 3. Vídeo institucional.

Fonte: Sítio CNA GO.

0 vídeo institucional da plataforma acontece em forma de narrativas, onde são apresentados dois personagens distintos: a Pipa, cujo objetivo é alcançar o cargo de gerência na empresa onde trabalha, e o Zen, que sonha em viajar de mochileiro pelo mundo. Ambos os personagens necessitam aprender inglês, o que os auxiliará a alcançar seus objetivos.

De acordo com Kapp, (2012), o cérebro humano tende a aprender mais rápido quando os fatos são contados em narrativas, o que caracteriza mais um elemento da gamificação. “As pessoas tendem a se lembrar dos fatos com mais precisão se os encontrarem em uma história, e não em uma lista [...] classificam os argumentos jurídicos como mais propriedade quando incorporados em contos narrativos do que em precedentes legais" (KAPP, 2012, p. 168)33.

Oliveira (2007, p. 6) também propõe “o uso de interfaces baseadas em narrativas e histórias, pois o nível de compreensão do estudante sobre as atividades desenvolvidas é ampliado quando está presente a estrutura de narrativa de uma história". Portanto, a plataforma CNA GO, utiliza-se desse recurso considerado tanto um elemento importante

\footnotetext{
3 Citação literal em idioma de origem: “People tend to remember facts more accurately if they encounter them in a story rather than in a list [...] they rate legal arguments as more convincing when built into narrative tales rather than in legal precedent".
}

LínguaTec, Instituto Federal de Educação, Ciência e Tecnologia do Rio Grande do Sul, Bento Gonçalves 
na gamificação, quanto uma característica que deve estar presente em interfaces voltadas ao aprendizado.

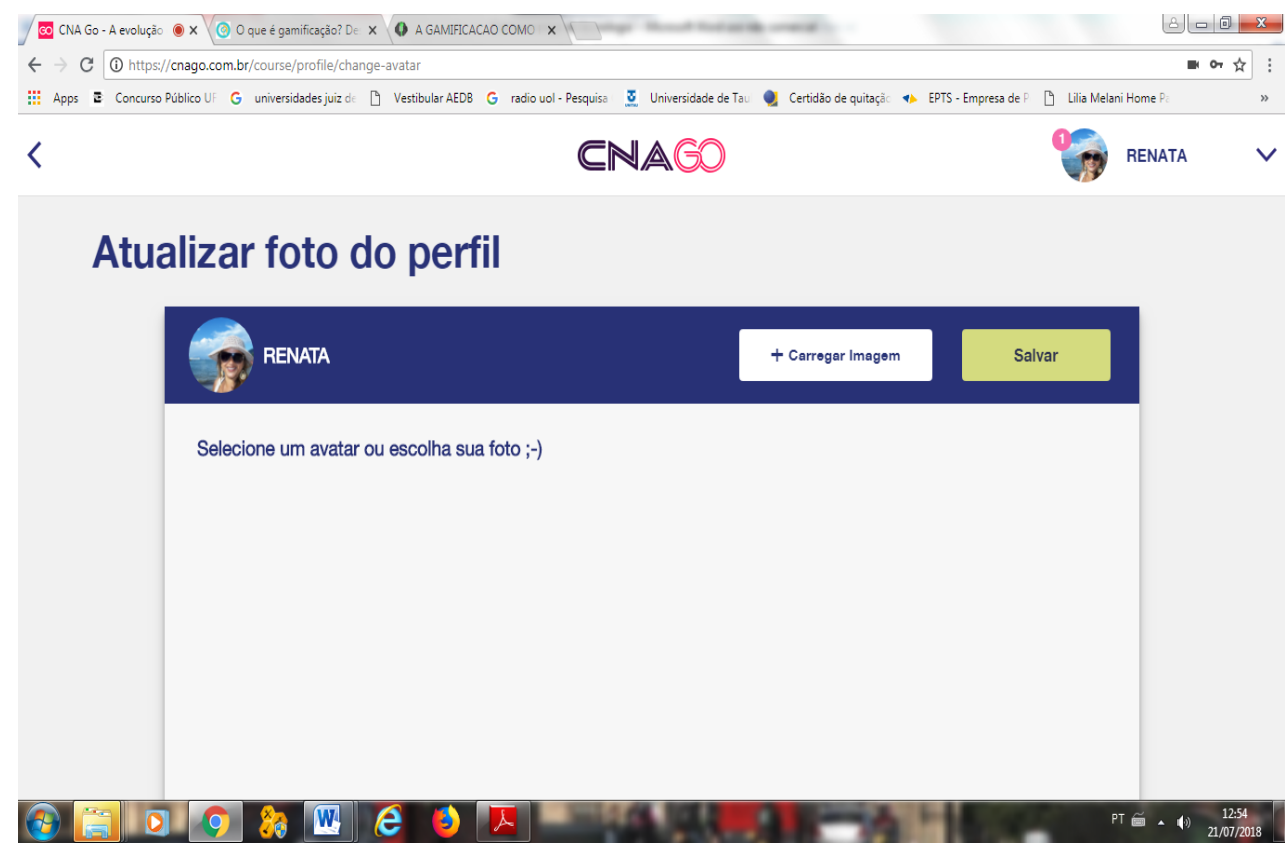

Figura 4. Escola do avatar. Fonte: Sítio CNA GO.

Um dos princípios de aprendizagem a partir dos bons jogos, apontados por Gee (2003) é o Princípio da Identidade. Segundo o autor, aprender requer que o aprendiz assuma uma nova identidade, comprometa-se com o mundo no qual irá atuar, tome um personagem ou construa um novo.

Aprender envolve assumir e brincar com identidades de tal maneira que o aprendiz tenha escolhas reais (no desenvolvimento da identidade virtual) e ampla oportunidade para meditar na relação entre novas identidades e antigas. Há um jogo tripartido de identidades à medida que os alunos se relacionam e refletem sobre suas múltiplas identidades do mundo real, uma identidade virtual e uma identidade projetiva (GEE, 2003, p. 64) 4 .

Werbach e Hunter apud Alves (2012, p.49), falam, especificamente, sobre o "avatar". Segundo eles, a escolha de avatares "mostra ao jogador alguma representação visual de seu personagem ou papel no sistema gamificado".

\footnotetext{
4 Citação literal em idioma de origem: “Learning involves taking on and playing with identities in such a way that the learner has real choices (in developing the virtual identity) and ample opportunity to meditate on the relationship between new identities and old ones. There is a tripartite play of identities as learners relate, and reflect on, their multiple real-world identities, a virtual identity, and a projective identity".
}

LínguaTec, Instituto Federal de Educação, Ciência e Tecnologia do Rio Grande do Sul, Bento Gonçalves v. 4 , n. 2 , p. 1-28, nov. 2019. 
Huizinga (2003) fala ainda sobre a fuga da realidade, uma das características dos jogos. Segundo o autor, "trata-se de uma evasão da vida 'real' para uma esfera temporária de atividade com orientação própria" (Huizinga, 2003, p. 10). A plataforma CNA Go possibilita ao aprendiz a escolha de um avatar. Dessa forma, ele assume uma identidade com a qual, durante o tempo em que estiver interagindo com a plataforma, poderá desligarse de sua vida cotidiana e embarcar nesta viagem rumo ao aprendizado da língua inglesa.

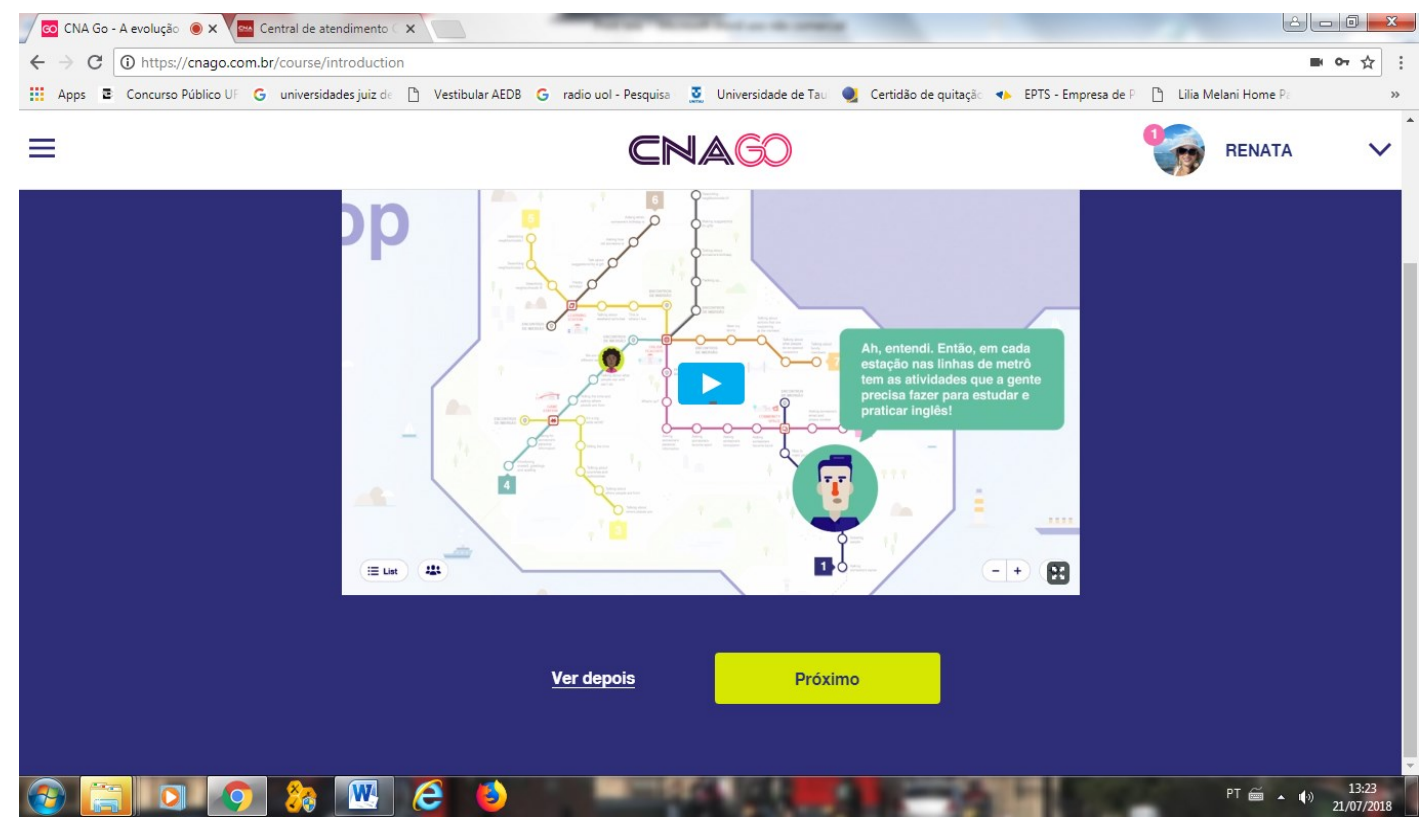

Figura 5. Mapa da viagem.

Fonte: Sítio CNA GO.

O cenário em que é mostrada a evolução do aprendiz sugere uma linha de trem. 0 aluno parte da estação quando inicia o curso e à medida em que vai avançando na realização das atividades propostas pela plataforma, avança também em sua “viagem”.

O design desse cenário imita um jogo de tabuleiro. 0 avatar é mostrado em cada trecho, para que o aprendente acompanhe e perceba seu avanço, assim como uma peça que se move num jogo de tabuleiro. Este elemento remete ao princípio de Agência de Gee (2003), onde o aprendiz, ao ter a possibilidade de acompanhar seu avanço, percebe o sentido real de gerenciamento e controle do seu aprendizado. “Princípio interno: o aluno é 'membro', 'professor' e 'produtor' (não apenas um 'consumidor'), capaz de personalizar a 
experiência de aprendizagem e o domínio/jogo desde o início e ao longo da experiência" (GEE, 2003, p. 197)5.

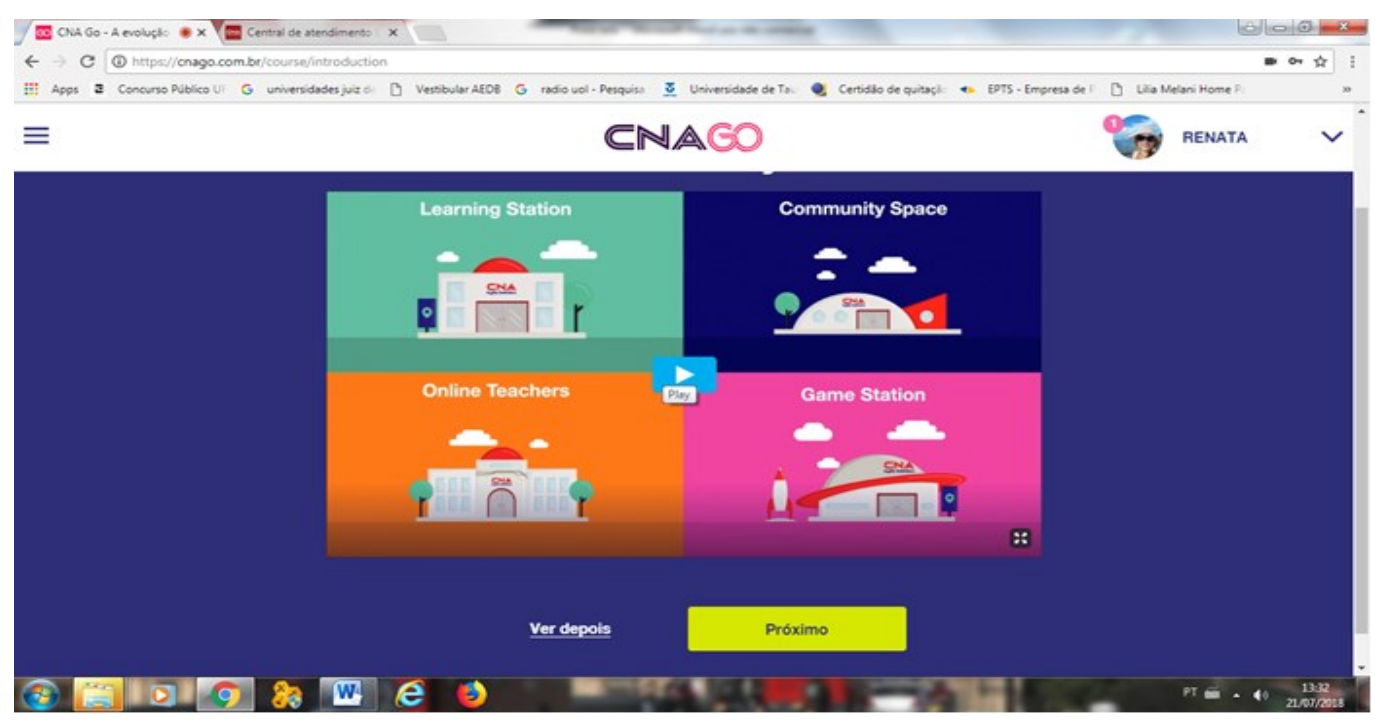

Figura 6. Cenário da viagem. Fonte: Sítio CNA GO.

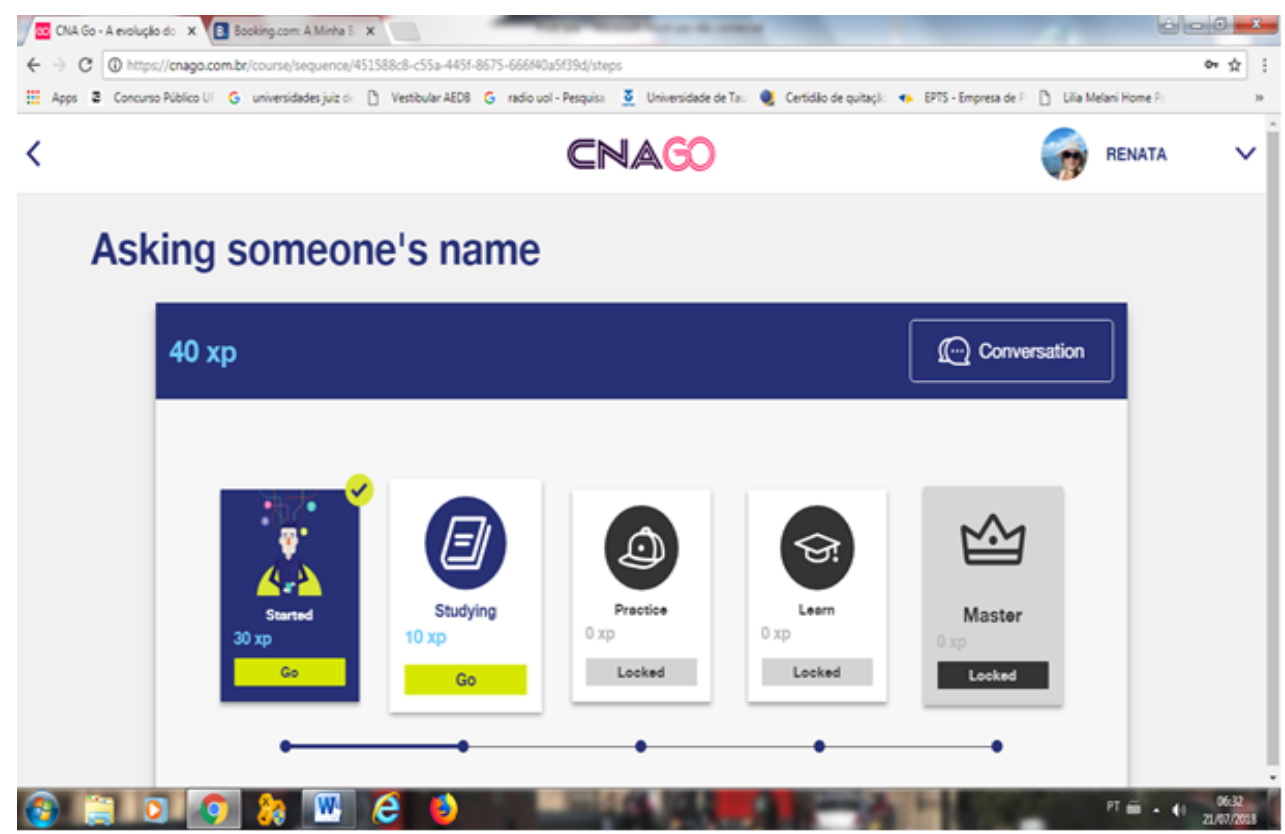

Figura 7. Liberação de etapas.

Fonte: Sítio CNA GO.

\footnotetext{
5 Citação literal em idioma de origem: 'Insider principle: the learner is an 'insider', 'teacher' and 'producer' (not just a 'consumer'), able to customize the learning experience and domain/game from the beginning and throughout the experience".
}

LínguaTec, Instituto Federal de Educação, Ciência e Tecnologia do Rio Grande do Sul, Bento Gonçalves 
Conforme observável na plataforma acima, há ambientes em que o acesso só é liberado à medida em que o aprendente obtém sucesso nas etapas anteriores.

Para Murta e Valadares (2010, apud VIANNA et al., 2013):

A gameficação (sic) é a utilização de mecanismos de jogos, os quais são divididos em cinco elementos. Um deles é o Acesso, que é um dos pontos estimuladores nos sistemas de recompensa para engajar os participantes em seus objetivos, pois a possibilidade de entrada em um ambiente, a permissão de uso de alguns recursos privilegiados, etc. ou a negação desses recursos servem para impulsionar os sujeitos no alcance das próximas etapas.

Tal fator remete também a um dos princípios de aprendizagem de Gee (2003. P. 71), o de desafio e consolidação, que oferece aos jogadores uma quantidade de problemas desafiadores e deixam que eles resolvam esses problemas até que tenham virtualmente rotinizado e automatizado suas soluções. Só assim os jogadores são desafiados a resolver um novo problema para que integrem essa nova aprendizagem à sua experiência. Portanto, nota-se aqui, mais um elemento da gamificação presente em tal ambiente de aprendizagem.

Princípio da Aprendizagem Contínua: a distinção entre aprendente e mestre é vaga, uma vez que os aprendentes, graças à operação do princípio do 'regime de competência' listado a seguir, devem, em níveis cada vez maiores, desfazer seu domínio rotineiro para se adaptarem a condições novas ou alteradas. Existem ciclos de novas aprendizagens, automatização, desconstrução da automatização e nova automatização reorganizada (GEE, 2003, p. 71) .

\footnotetext{
${ }^{6}$ Citação literal em idioma de origem: “Ongoing Learning Principle: the distinction between learner and master is vague, since learners, thanks to the operation of the 'regime of competence' principle listed next, must, at higher and higher levels, undo their routinized mastery to adapt to new or changed conditions. There are cycles of new learning, automatization, undoing automatization, and new reorganized automatization".
}

LínguaTec, Instituto Federal de Educação, Ciência e Tecnologia do Rio Grande do Sul, Bento Gonçalves v. 4 , n. 2, p. 1-28, nov. 2019. 


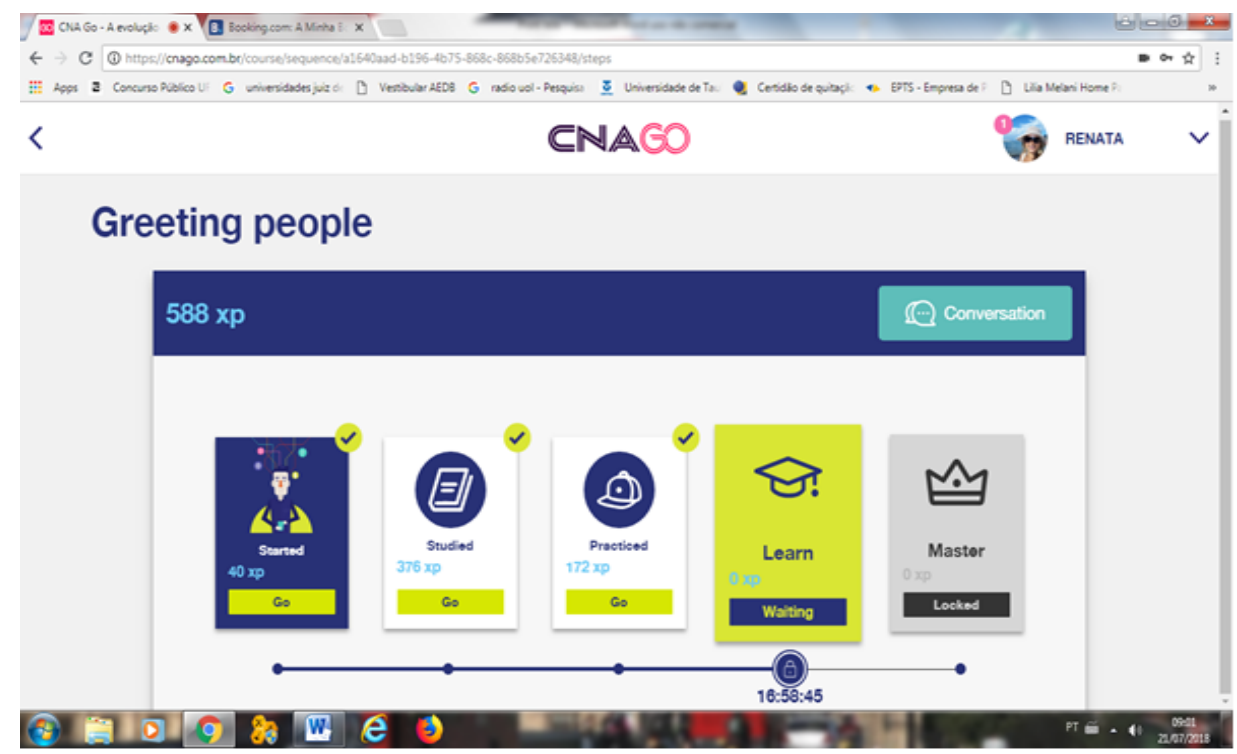

Figura 8. Tempo e espaço Fonte: Sítio CNA GO.

Segundo Huizinga (2000), as limitações de tempo e espaço, são duas características dos jogos.

0 jogo distingue-se da vida "comum" tanto pelo lugar quanto pela duração que ocupa. É esta a terceira de suas características principais: o isolamento, a limitação. É "jogado até ao fim" dentro de certos limites de tempo e de espaço. Possui um caminho e um sentido próprios (HUIZINGA, 2000, p. 11).

Na plataforma em análise, 0 aprendente tem um limite de tempo para realizar as tarefas em cada etapa. A medida em que vai cumprindo as atividades e vai avançando no “jogo", o tempo vai sendo cronometrado. 


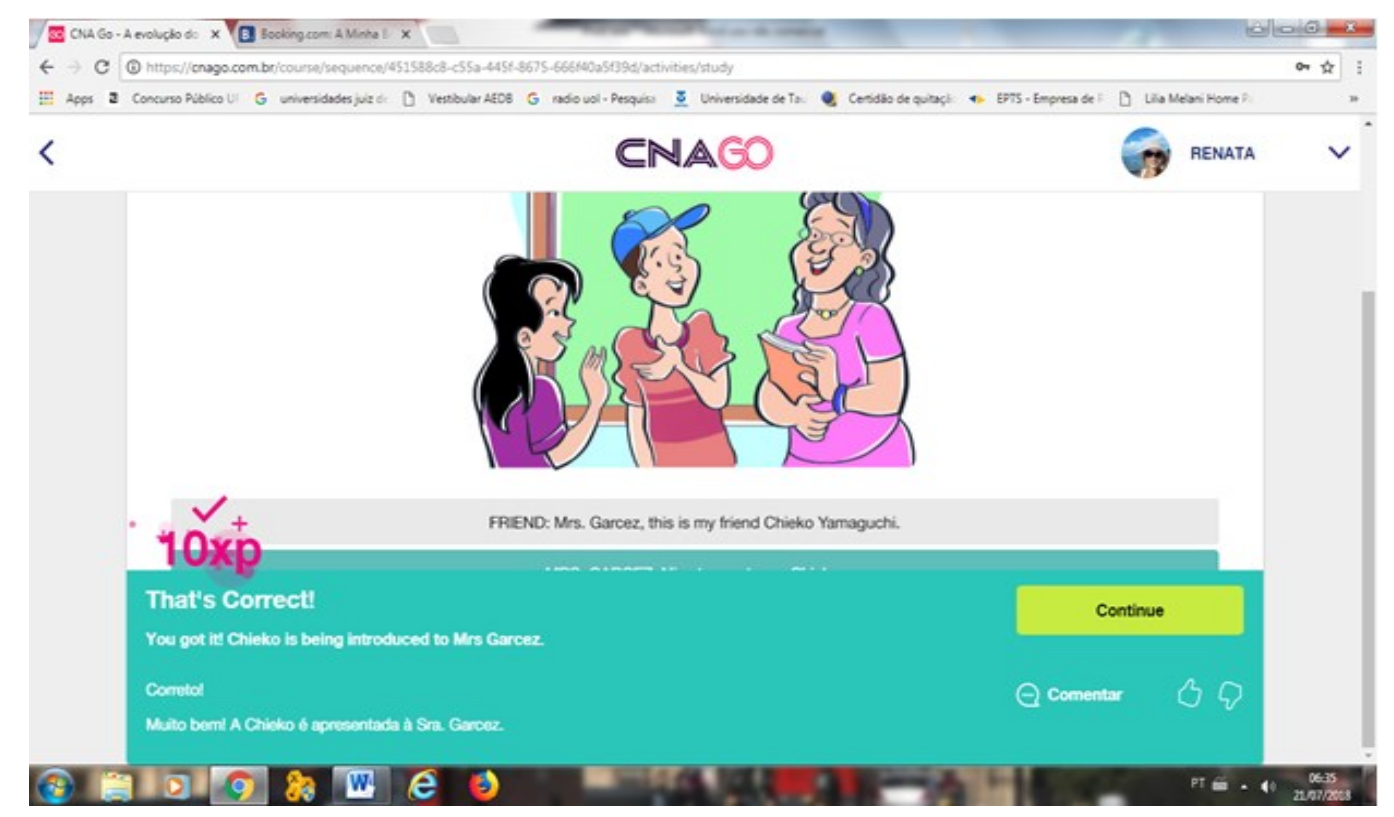

Figura 9. Feedback.

Fonte: Sítio CNA GO.

Para Vianna et al. (2013), o feedback é importante para garantir o engajamento nas atividades. Conforme observável, a plataforma oferece um feedback imediato à ação do aprendente, possibilitando a ele avaliar suas ações e expandir seu conhecimento, através dos comentários.

Gee (2003) também aponta o que ele chama de "a tempo e sob demanda7" como um princípio de aprendizagem a partir de bons jogos, pois, quando o feedback é imediato, possibilita ao aprendente refletir sobre suas ações para a realização de suas tarefas.

Princípio explícito da demanda por informações explícitas sob demanda: 0 aluno recebe informações explícitas sob demanda e em oportunidade oportuna, no momento em que o aluno necessite delas ou apenas no ponto em que as informações podem ser melhor entendidas e usadas na prática (GEE, 2003, p. $211)^{8}$.

Para Gee (2003), as pessoas aprendem melhor, quando têm um feedback imediato de suas ações.

\footnotetext{
${ }^{7}$ Citação literal em idioma de origem: "Just in time e on demand".

${ }^{8}$ Citação literal em idioma de origem: "Explicit Information On-Demand Just-in-Time Principle: The learner is given explicit information both on-demand and just-in-time, when the learner needs it or just at the point where the information can best be understood and used in practice".
}

LínguaTec, Instituto Federal de Educação, Ciência e Tecnologia do Rio Grande do Sul, Bento Gonçalves 


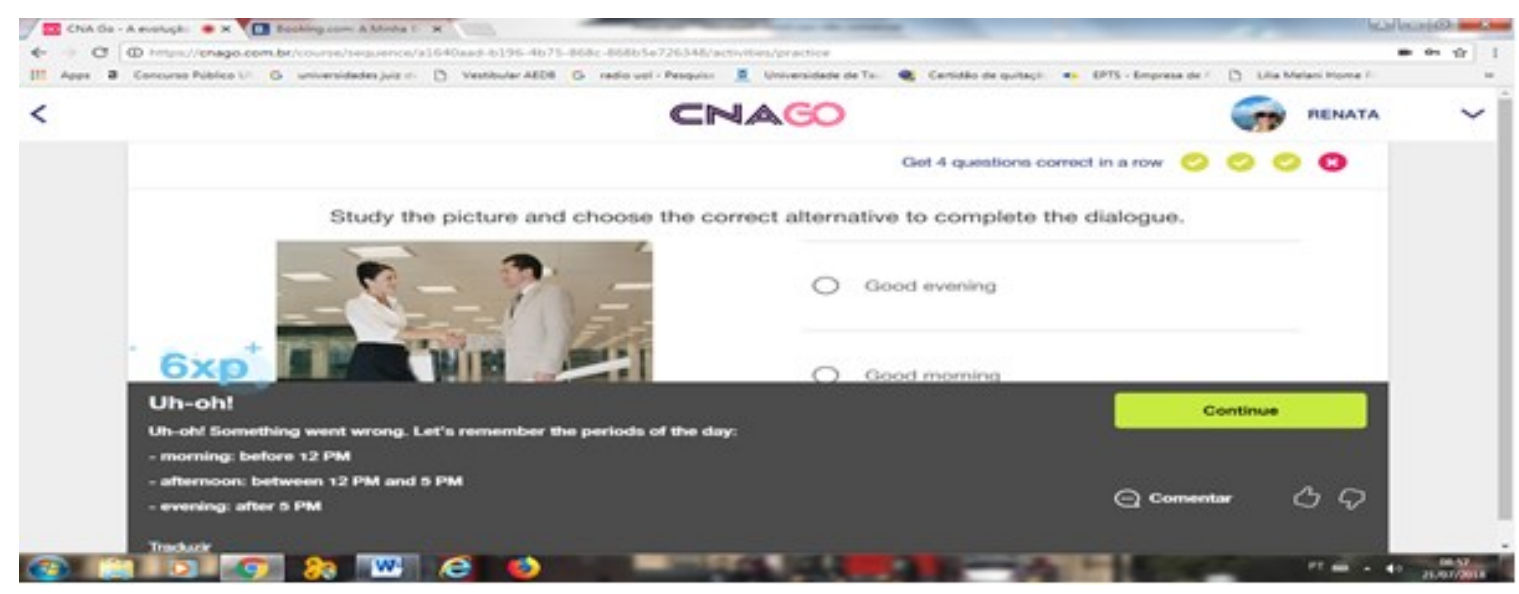

Figura 10. Desafio 1.

Fonte: Sítio CNA GO.
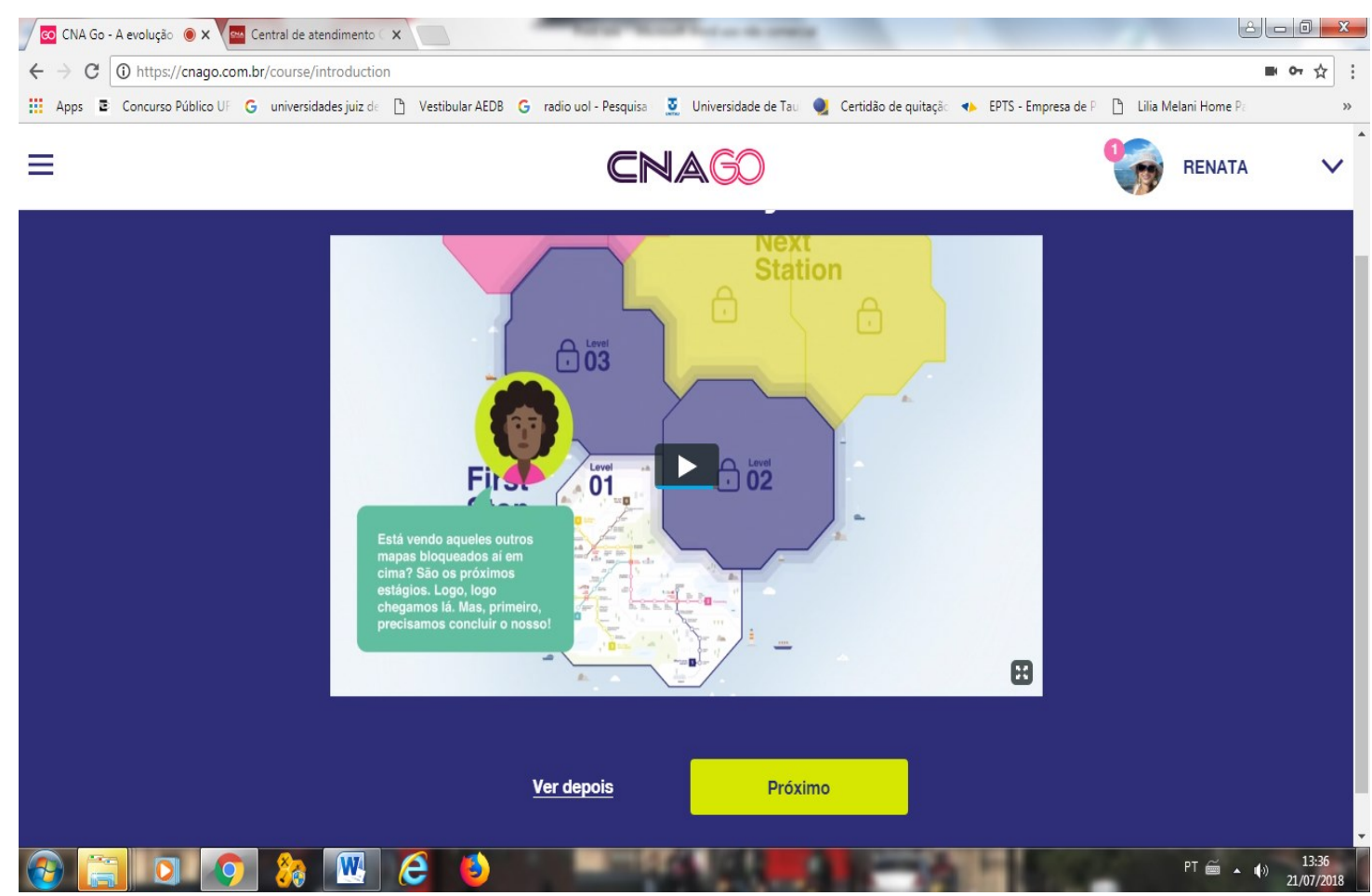

Figura 11. Desafio 2.

Fonte: Sítio CNA GO.

O trecho destacado na Figura 10 possui o seguinte texto: “Está vendo aqueles outros mapas bloqueados aí em cima? São os próximos estágios. Logo, logo chegaremos lá. Mas, primeiro, precisamos concluir o nosso!". Aqui podemos observar um dos princípios de aprendizagem apontados por Gee (2003): o do Desafio e consolidação, pois os aprendentes são desafiados a concluírem as atividades para terem acesso ao ambiente bloqueado.

LínguaTec, Instituto Federal de Educação, Ciência e Tecnologia do Rio Grande do Sul, Bento Gonçalves v. 4 , n. 2, p. 1-28, nov. 2019. 
Na Figura 9, ao mesmo tempo em que o aluno é desafiado a responder quatro questões corretas em seguida, ele assume riscos de errar e não vencer o desafio. Assumir riscos também é um princípio de aprendizagem a partir dos bons jogos, apontado por Gee (2003). “Moratória psicossocial: o aluno principiante pode correr riscos em um espaço onde as consequências do mundo real são reduzidas" (GEE, 2003, p. 67)99.

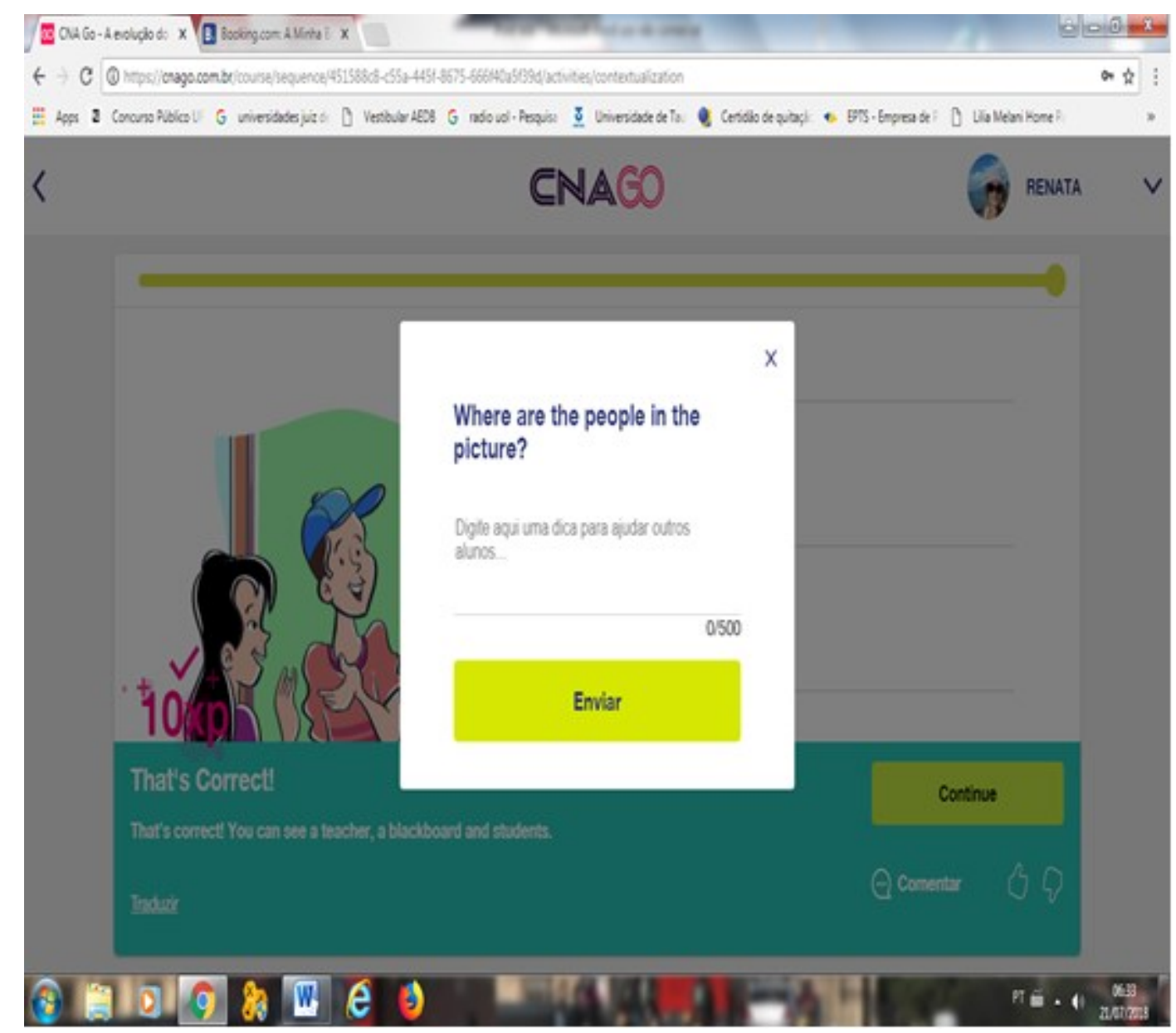

Figura 12. Desafio 3.

Fonte: Sítio CNA GO.

O princípio da Produção também é destacado por Gee (2003, p. 197). Conforme pode-se observar na Figura 11, o aprendente tem a possibilidade de digitar uma "dica" para os outros alunos, o que dá a ele, ao mesmo tempo, uma autonomia em seu aprendizado e a capacidade de produzir, de compartilhar seus conhecimentos com os demais aprendentes.

9 Citação literal em idioma de origem: "Psychosocial Moratorium: principle learners can take risks in a space where real-world consequences are lowered".

LínguaTec, Instituto Federal de Educação, Ciência e Tecnologia do Rio Grande do Sul, Bento Gonçalves v. 4 , n. 2 , p. 1-28, nov. 2019. 
Outro elemento que também pode ser observável nessa possibilidade de ação é o da Influência. Para Vianna et al. (2013, p. 12) ela acontece quando um jogador tem a possibilidade de interferir positiva ou negativamente, voluntária ou involuntariamente no andamento de outrem. Isso pode ocorrer no momento em que o aprendente digita sua “dica”, a qual será acessada pelos outros alunos, interferindo no aprendizado destes de uma forma positiva ou negativa.

A influência pode ser concedida aos jogadores de forma direta ou indireta. A primeira permite que o usuário tenha a sensação de controle no jogo, podendo ser concedida a ele por meio de algum benefício ou conquista durante o jogo. A segunda acontece quando um jogador tem a possibilidade de interferir positiva ou negativamente, voluntária ou involuntariamente no andamento de outrem (MURTA; VALADARES, 2010, apud VIANNA et al., 2013, p. 12).

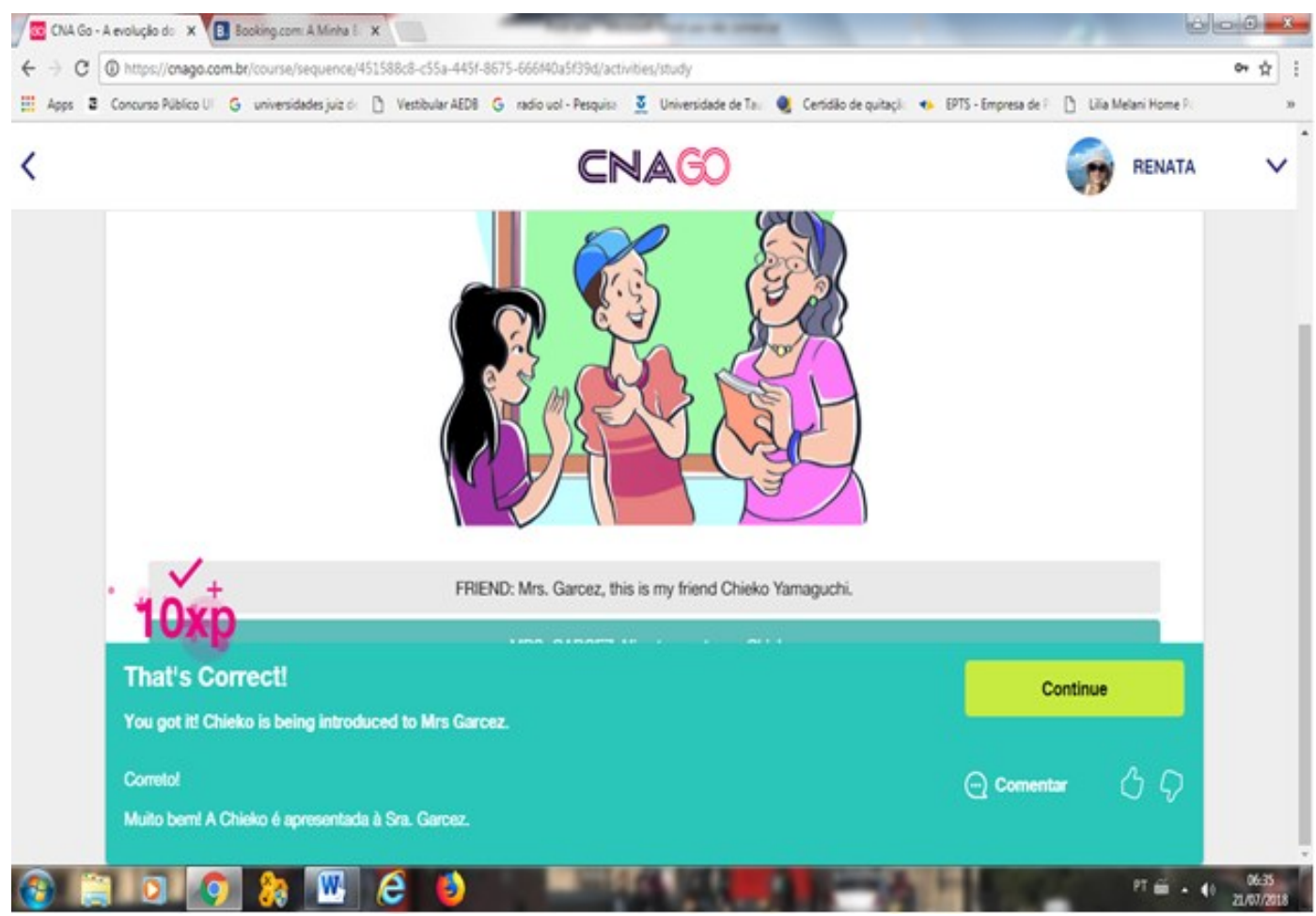

Figura 13: Interação plataforma x aluno 1.

Fonte: Sítio CNA GO.

Resume Gee (2003) que, em um bom jogo, as palavras são colocadas em contexto, em uma relação interativa do jogador com o mundo. Esse é o princípio da Interação. Conforme apresentado na Figura 12, a plataforma interage com 0 aluno, como se fosse 0 
professor em constante diálogo com o mesmo, incentivando-o e motivando-o a continuar e suceder em suas atividades.

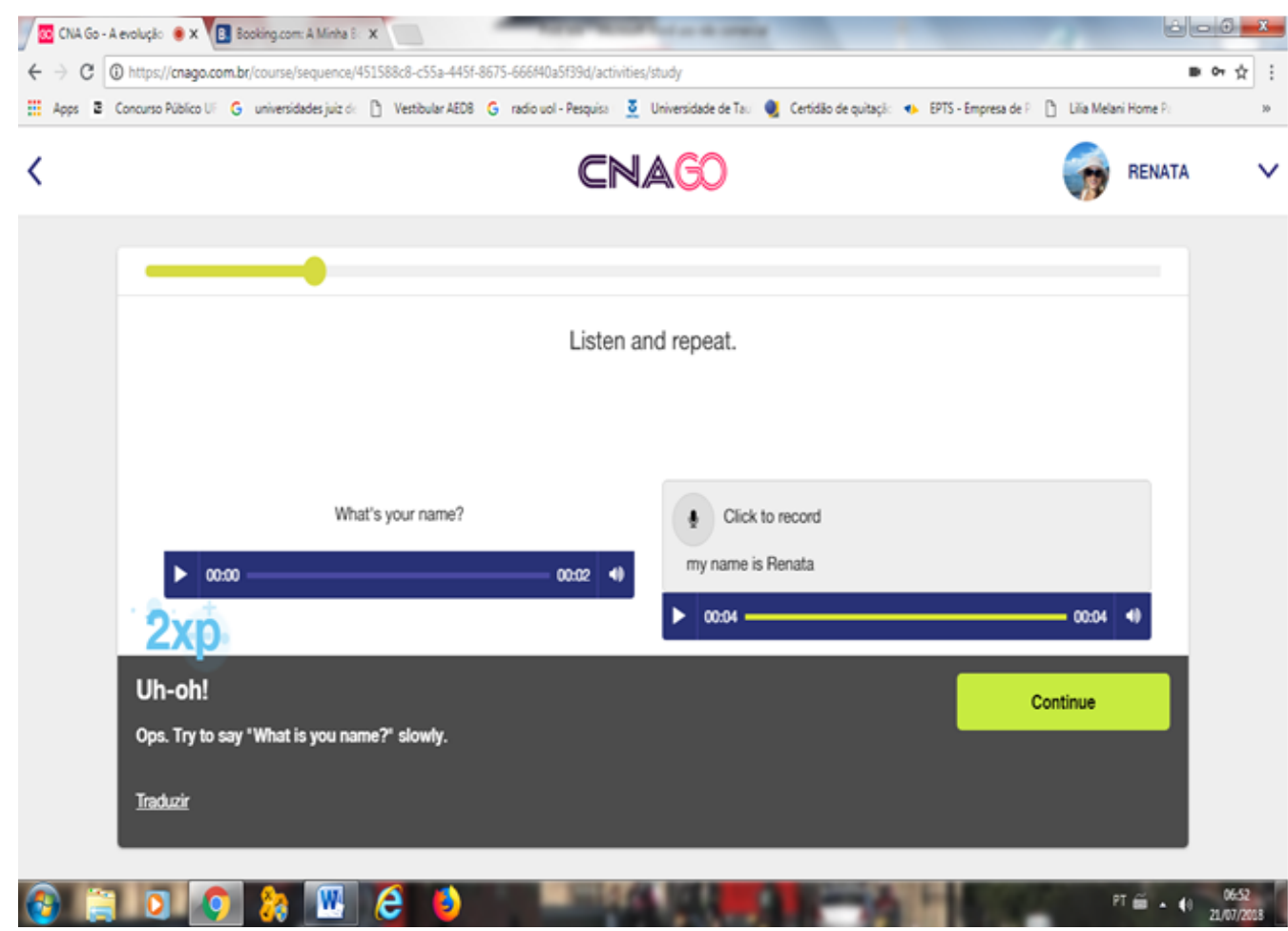

Figura 14. Interação plataforma x aluno 2.

Fonte: Sítio CNA GO.

Segundo Oliveira (2007, p. 6), um dos critérios de avaliação de um ambiente virtual de ensino é a Interatividade que pode ser da interface com o aluno e do aluno com o professor. As figuras acima demonstram possibilidades de interação entre a interface e o usuário/aprendente numa atividade de gravação de aúdio, onde o aluno é levado a dizer qual é o seu nome.

A avaliação da oralidade em um ambiente virtual é um requisito importante no aprendizado de língua estrangeira através de um ambiente virtual de ensino. A plataforma em estudo dá essa possibilidade ao aluno, porém, observou-se uma dificuldade imensa do sistema em relação ao conhecimento da fonética do nome Renata. 0 sistema tranpôs para a escrita diversas formas errôneas do nome e mesmo quando, finalmente, o nome Renata foi escrito corretamente, o sistema, ainda assim, não reconheceu como correto. Por fim, não se obteve sucesso na realização desta atividade não por erro do aprendente, mas falha do sistema.

LínguaTec, Instituto Federal de Educação, Ciência e Tecnologia do Rio Grande do Sul, Bento Gonçalves v. 4 , n. 2 , p. 1-28, nov. 2019. 

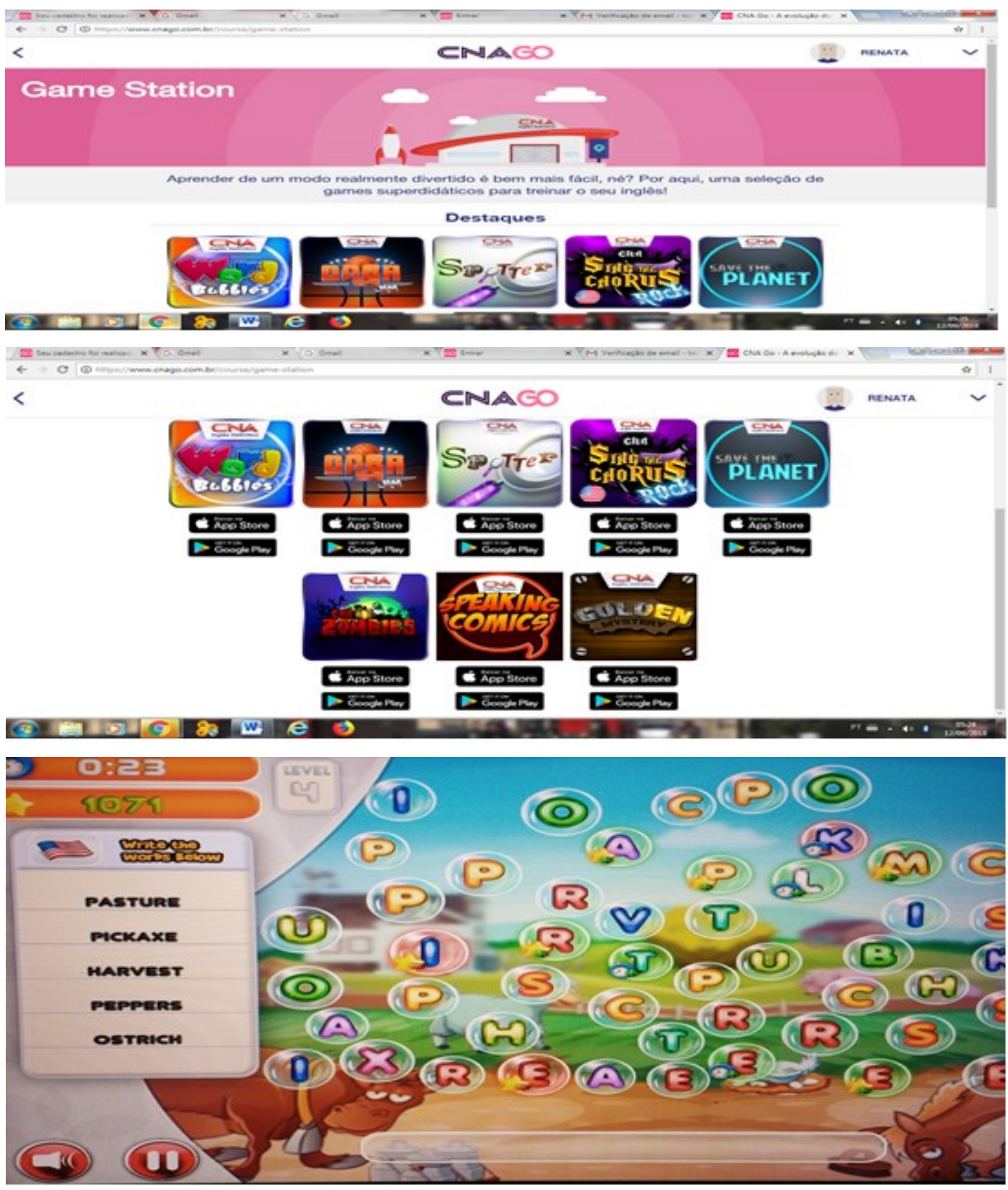

Figura 15. Game station.

Fonte: Sítio CNA GO.

Finalmente, além dos elementos de gamificação presentes na plataforma, ela ainda possui uma "Game Station", onde o aprendente tem disponíveis doze diferentes jogos que exploram as habilidades de escrita, leitura, formação de palavras, jogos estes que também

LínguaTec, Instituto Federal de Educação, Ciência e Tecnologia do Rio Grande do Sul, Bento Gonçalves v. 4 , n. 2 , p. 1-28, nov. 2019. 
apresentam características, princípios de aprendizagem a partir de bons jogos, e elementos facilitadores para o aprendizado provindos dos jogos, possibilitando um aprendizado de forma lúdica.

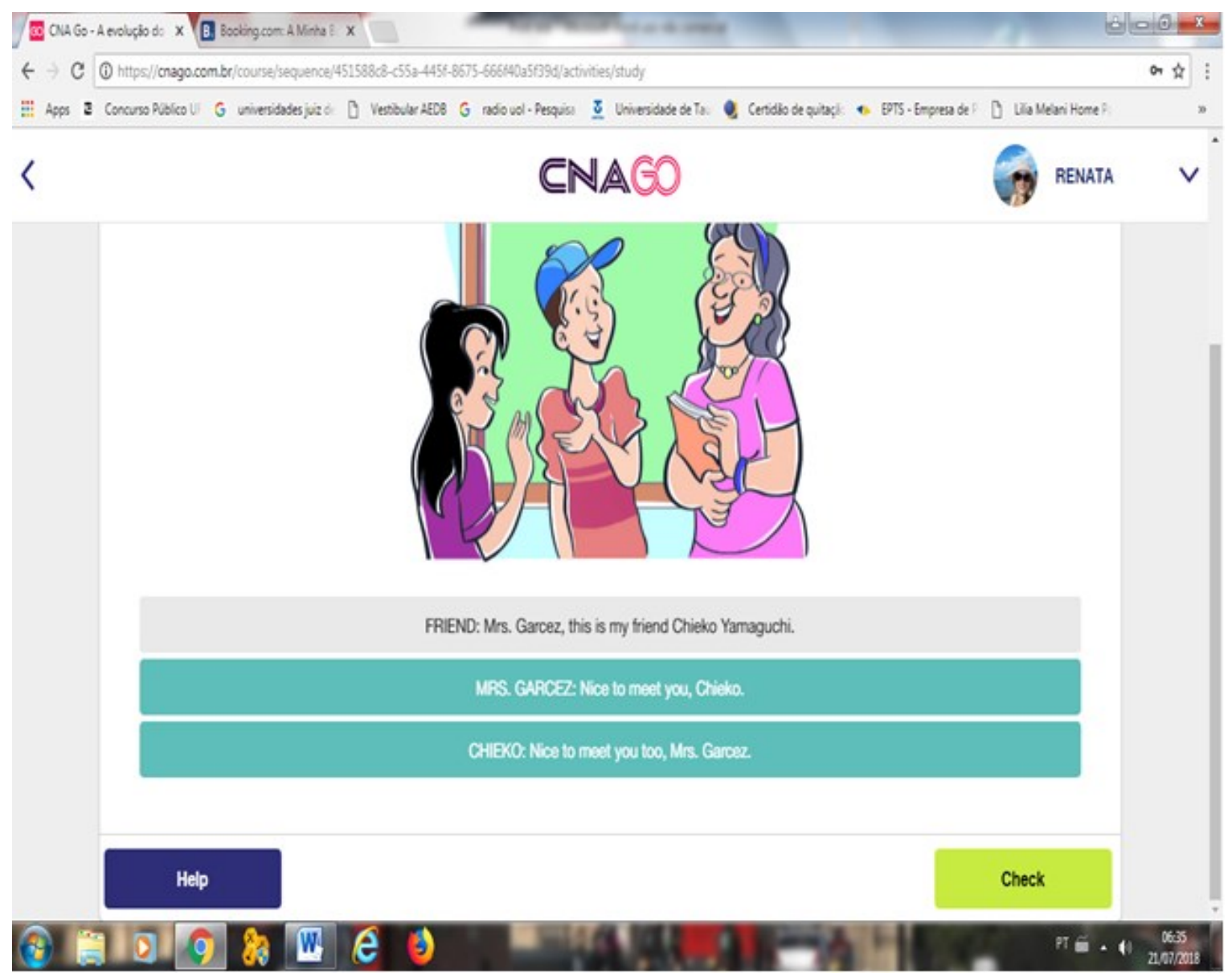

Figura 16. Interface (livro didático). Fonte: Sítio CNA GO.

De acordo com Oliveira, num ambiente virtual voltado para a aprendizagem, o material didático digital deve ser "acompanhado de texto falado, sons, cores, movimentos, etc., caracterizando o uso dos recursos multimídia" e não apenas uma mera transposição do livro didático para a tela. “É, no mínimo, uma impropriedade usar a tela do computador apenas como página de livro, sem um devido e aprofundado estudo em todas as suas instâncias". (OLIVEIRA, 2006, p. 7).

Nesse ítem, a plataforma não se apossou dos recursos multimidiáticos disponíveis. Por tratar-se de um material didático num amviente virtual, poderia apresentar os diálogos 
e situações através de vídeos, por exemplo, o que seria impossível em um material didático impresso. Porém, apenas transpôs para a tela o ambiente do material impresso.
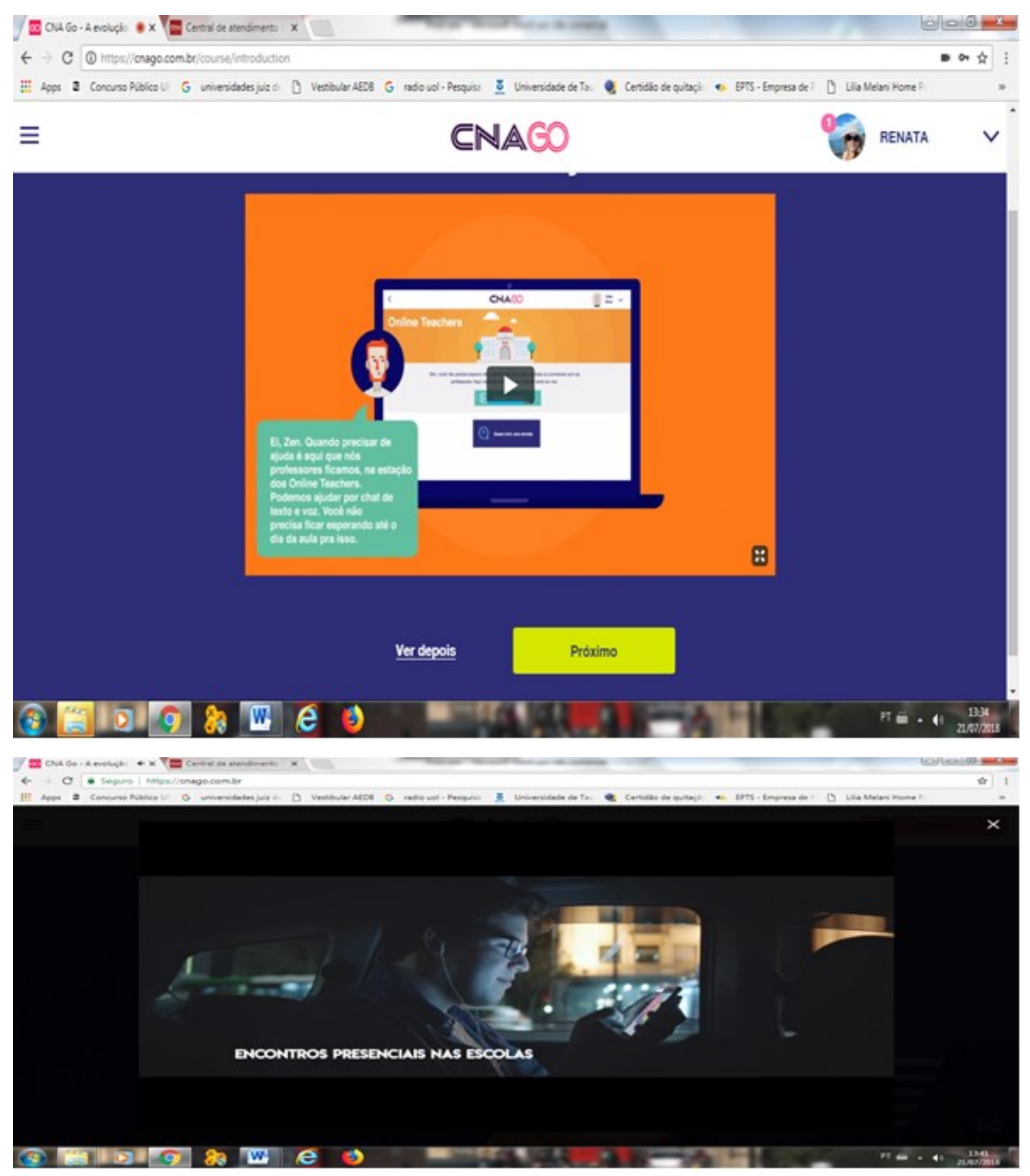

Figura 17. Interação aprendente e professor.

Fonte: Sítio CNA GO.

Para Oliveira (2007, p. 3), o ambiente virtual de aprendizagem deve suprir a ausência do professor. Para isso, a interatividade deve ser eficaz, diminuindo a falta física do docente.

LínguaTec, Instituto Federal de Educação, Ciência e Tecnologia do Rio Grande do Sul, Bento Gonçalves v. 4 , n. 2 , p. 1-28, nov. 2019. 
Na conversa através de chats "considerar o texto escrito somente um misto de oralidade e escrita é, conforme Barros (2001, p. 361), ignorar a falta de sincronização das ações dos participantes pela ausência, tanto do contato visual quanto auditivo." (OLIVEIRA, 2007, p. 3).

De acordo com as imagens acima, a plataforma CNA Go possibilita ao aprendente a oportunidade não somente de interação através de chats escritos ou com áudio, mas também a possibilidade de aulas presenciais nos espaços físicos da instituição de ensino. Tais fatores demonstram que a interação se mostra eficaz de acordo com o que os teóricos apontam.

\section{Resultados}

Como resumo dos itens analisados em relação à gamificação, segue quadro composto por itens que Vianna et al. (2013), descritos da subseção 2.3 do presente artigo acadêmico, considera na avaliação da temática.

\begin{tabular}{|c|c|}
\hline $\begin{array}{c}\text { Componentes de gamificação segundo } \\
\text { Vianna et al. (2013). }\end{array}$ & $\begin{array}{c}\text { Avaliação dos componentes de gamificação } \\
\text { na plataforma analisada. }\end{array}$ \\
\hline Status & Presente de forma satisfatória \\
\hline Acesso & Presente de forma satisfatória \\
\hline Influência & Presente de forma satisfatória \\
\hline Brindes e Giftings & Presente de forma satisfatória \\
\hline
\end{tabular}

Confirmou-se na análise dos dados desta pesquisa, que a plataforma virtual de aprendizagem de Língua Inglesa e Espanhola CNA Go trata-se de um ambiente gamificado, pois apresenta características, princípios e elementos de jogos desde a sua tela de boasvindas, até a finalização das unidades. Seu design simula uma jornada, onde o aluno/usuário embarca em uma viagem de trem, rumo ao aprendizado da língua inglesa. 0 cenário simula um jogo de tabuleiro, onde as paisagens vão sendo apresentadas ao usuário, na medida em que ele vai avançando na viagem. Para avançar, basta ser bem-sucedido nas atividades que 
são propostas sob a forma de um jogo, com características como desafios, premiações, limite de tempo, feedback.

Ao usuário é dada a opção de interagir na plataforma através da escolha de um avatar ou com a sua própria foto, possibilitando que ele assuma uma nova identidade. As atividades apresentam princípios de aprendizagem a partir de bons jogos, tais como interação, identidade, agência, entre outros.

Além de um ambiente gamificado, a plataforma ainda disponibiliza uma Game Station, com doze opções de jogos, os quais também apresentam características dos "bons jogos", com suma importância para a aprendizagem.

Finalmente, no que diz respeito à interface de um ambiente destinado à aprendizagem, foram encontradas algumas falhas, tais como dificuldade do sistema no reconhecimento da fonética do nome Renata, além de apresentar o conteúdo das atividades como uma mera transposição do material didático impresso, não usufruindo do princípio da multimodalidade, provindo de ambientes virtuais de aprendizagem. Em contrapartida, critérios como o design, usabilidade e interatividade estão presentes de forma eficiente ao ensino da língua inglesa, através de um AVA.

\section{Considerações finais}

Observou-se que a que a plataforma tema deste artigo acadêmico é uma plataforma de ensino gamificada e dispõe de atividades onde o aluno/aprendente vivencia a experiência de um jogo, possibilitando um aprendizado de forma lúdica.

No que diz respeito do ambiente virtual, algumas falhas foram apontadas, tais como o não uso dos recursos da multimodalidade, fazendo com que as atividades fossem uma mera transposição do livro didático para a tela do computador e dificuldades do sistema no reconhecimento fonético de palavras, especificamente do nome "Renata".

Com base na teoria dos estudiosos citados neste trabalho, pode-se concluir que a plataforma CNA Go demonstra ser um ambiente eficiente ao ensino da língua inglesa, pois apresenta inúmeros recursos e elementos considerados eficazes ao ensino. 
Como sugestão para futuras pesquisas, pode-se ampliar a análise da interface em si, observando mais critérios a serem avaliados em um ambiente virtual de aprendizagem (AVA), sobre tudo a interatividade.

Finalmente, espera-se que esta pesquisa possa contribuir para o meio acadêmico, e servir como base para avaliar diferentes ambientes virtuais de ensino similares à plataforma CNA Go, mas não se restringindo a sistemas voltados para o ensino de idiomas estrangeiros, mas para ensino como um todo.

\section{Referências}

ALVES, F. Gamification: como criar experiências de aprendizagem engajadoras - um guia completo do conceito à prática. São Paulo: DVS, 2014.

BURKE, B. Gamificar: como a gamificação motiva as pessoas a fazerem coisas extraordinárias. São Paulo: DVS, 2015.

GEE, P. Bons videogames e boa aprendizagem. Perspectiva. Florianópolis, v. 27, n. 1, p. 167178, 2009. Disponível em:

https://periodicos.ufsc.br/index.php/perspectiva/article/viewFile/15838/14515. Acesso em 27 nov. 2018.

GEE, P. What video games have to teach us about learning and literacy. Nova York: Macmillan, 2003.

HUIZINGA, J. Homo Ludens. 4 ed. São Paulo: Perspectiva, 1990.

KAPP, K. M. The Gamification of Learning and Instruction. San Francisco: Pfeiffer, 2012.

MURTA, C. R.; VALADARES M. G. P. F. Princípios de aprendizagem de jogos eletrônicos: gameficando a aula de línguas. Horizontes de Linguística Aplicada. Brasília, v. 1, n. 1, p. 4161, 2013. Disponivel em: http://periodicos.unb.br/index.php/horizontesla/article/viewFile/11795/10851. Acesso em 27 nov. 2018.

OLIVEIRA, C. A. A mídia computacional e sua outra linguagem. Acta Semiotica et Lingvistica. João Pessoa, v.11, n. 30, p.137-148, 2007. Disponível em: https://user68731098986.cld.bz/A-MIDIA-COMPUTACIONAL-E-SUA-OUTRA-LINGUAGEM. Acesso em 27 nov. 2018. 
VIANNA, Y.; VIANNA, M.; MEDINA, B.; TANAKA, S. Gamification, Inc: como reinventar empresas a partir de jogos. Rio de Janeiro: MJV Press, 2013.

Data de submissão: 06/07/2019. Data de aprovação: 21/10/2019. 